\title{
Kinetics of adenylate metabolism in human and rat myocardium
}

\author{
Monique Tavenier ${ }^{a}$, Andrzej C. Skladanowski ${ }^{b}$, Ronney A. De Abreu ${ }^{c}$, \\ Jan Willem de Jong ${ }^{\mathrm{a}, *}$ \\ "Cardiochemical Laboratory, Thoraxcenter, Erasmus University Rotterdam, Room Ee 2371, P.O. Box 1738, 3000 DR Rotterdam, Netherlands \\ ${ }^{\mathrm{b}}$ Department of Biochemistry, Academic Medical School, ul. Debinki 1, 80-211 Gdańsk, Poland \\ 'Pediatric Institute, Academic Hospital Nijmegen, Nijmegen, Netherlands
}

Received 10 January 1994; revised 10 January 1995; accepted 7 March 1995

\begin{abstract}
Pathways producing and converting adenosine have hardly been investigated in human heart, contrasting work in other species. We compared the kinetics of enzymes associated with purine degradation and salvage in human and rat heart cytoplasm assaying for adenosine deaminase, nucleoside phosphorylase, xanthine oxidoreductase, AMP deaminase, AMP- and IMP-specific 5'-nucleotidases, adenosine kinase and hypoxanthine guanine phosphoribosyltransferase (HGPRT). Xanthine oxidoreductase was not detectable in human heart. The $K_{\mathrm{m}}$-values of the AMP-catabolizing enzymes were 2-5 times higher in human heart; the substrate affinity of the other enzymes was in the same order of magnitude in both species. The maximal activity $\left(V_{\max }\right)$ of adenosine kinase was the same in both species, but HGPRT in man was only $12 \%$ of that in the rat. For human heart the $V_{\max }$-values of adenosine deaminase, nucleoside phosphorylase, AMP- and IMP-specific 5'-nucleotidases, and AMP deaminase were 25-50\% of those for rat heart. We conclude that human heart is less geared to purine catabolism than rat heart as is evident from the lower activities of the catabolic enzymes. Maintenance of the nucleotide pool may thus play a more important role in human heart.
\end{abstract}

Keywords: Adenosine; Adenylate metabolism; Enzymology; Heart; Human; Rat

\section{Introduction}

Adenosine plays an important role in several cardiovascular processes. It is a potent vasodilator with depressant effects on contractility, heart rate and conductance of the pacemaker nodes [1]. The nucleoside may protect the heart by 'preconditioning' through $\mathrm{A}_{1}$-receptor activation [2]. The pathways that produce and catabolize adenosine in hearts of several nonprimates have extensively been studied. In contrast, the activity and regulation of enzymes involved in purine-nucleotide metabolism, like AK, ADA,

Abbreviations: ADA: adenosine deaminase; AK: adenosine kinase; AMP-D: AMP deaminase; AOPCP: adenosine $(\alpha, \beta$-methylene)diphosphate; DTT: dithiothreitol; EHNA: erythro-9-(2-hydroxy-3-nonyl)adenine; HGPRT: hypoxanthine guanine phosphoribosyltransferase; NP: nucleoside phosphorylase; NSC 113939: 4-amino-5-iodo-7-( $\beta$-Dribofuranosyl)7H-pyrrolo[2,3-d]pyrimidine; $5^{\prime}$-NT: $5^{\prime}$-nucleotidase; PRPP: phosphoribosylpyrophosphate; SAH: S-adenosylhomocysteine; XOD: xanthine oxidoreductase

* Corresponding author. Fax: (31)-10-4365607.
NP, AMP-D and HGPRT, have been investigated to a lesser extent in human tissues (see footnote for abbreviations). Also the presence of two isozymes of $5^{\prime}$-NT differing in substrate preferences (AMP- and IMP-specific) found in various animal hearts [3] has not been confirmed in human heart. Fig. 1 shows the pathways involved. Deactivation of adenosine is possible through rapid breakdown by ADA. This happens both inside and outside the cell [4]; the cellular process has been studied more thoroughly and is likely to be more important. ADA activity varies considerably in hearts of different species [5]. Metabolic inhibitors for purine degradation, such as allopurinol and EHNA, are in use in cardioplegic solutions [6-8], as are adenosine catabolites like inosine to treat heart failure $[9,10]$. Those clinical trials assume the presence and activity of certain enzymes in the human heart. However, the enzymological background for such studies is absent.

The purpose of this study was to investigate the kinetics of cytosolic purine-metabolizing enzymes in human heart, with emphasis on the regulation of the adenosine level. This could give therapy and diagnostics with adenosine a 


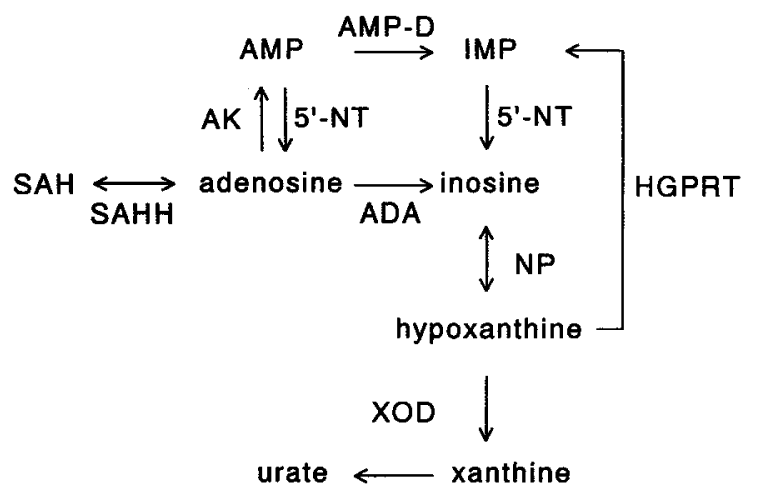

Fig. 1. Pathways of purine metabolism in rat and human heart. The conversions of hypoxanthine to xanthine and to urate catalyzed by XOD are probably absent in human heart. ADA, adenosine deaminase; $\mathrm{AK}$, adenosine kinase; AMP-D, AMP deaminase; HGPRT, hypoxanthine guanine phosphoribosyltransferase; NP, nucleoside phosphorylase; $5^{\prime}-\mathrm{NT}$, 5 '-nucleotidase; SAHH, S-adenosylhomocysteine hydrolase; XOD, xanthine oxidoreductase.

better fundamental basis. We compared the human-heart data with those from rat heart, which is well described as a metabolic system.

\section{Materials and methods}

\subsection{Human and rat myocardial homogenates}

Human hearts were obtained from transplantation patients with end-stage heart failure (cardiomyopathy, hypertrophy, atherosclerosis, myocarditis etc.) of the Thoraxcenter, Erasmus University Rotterdam. The hearts were arrested with cold St. Thomas' Hospital cardioplegic solution, excised and cooled on ice; they arrived in the laboratory within $10 \mathrm{~min}$. Nonfibrotic samples from the leftventricular wall were cut into pieces. Some control experiments $(n=4)$ were done on healthy donor hearts, unused for transplantation for clinical reasons. Because the kinetic data obtained were comparable to the ones from explanted diseased hearts, the data were pooled. Hearts were also obtained from anesthetized male adult Wistar rats (250-270 g) as described before [11]. For the AMP-D assay, 10\% $(\mathrm{w} / \mathrm{v})$ homogenates were made in $20 \mathrm{mM} \mathrm{Na}{ }^{+}$-dimethylglutarate (pH 7.4), $1 \mathrm{mM}$ EDTA and $0.1 \mathrm{mM}$ DTT. For HGPRT $20 \%(\mathrm{w} / \mathrm{v})$ homogenates were made in $0.5 \mathrm{M}$ Tris and $0.05 \mathrm{M} \mathrm{MgCl}_{2}(\mathrm{pH} 7.4)$. The other assays were carried out in $5 \%(\mathrm{w} / \mathrm{v})$ homogenates prepared as previously described [11]. The 5 and $10 \%$ homogenates were centrifuged (Sigma 2K15, Braun, Melsungen, Germany) for $5 \mathrm{~min}$, at $12000 \times \mathrm{g}$ and $4^{\circ} \mathrm{C}$, whereas the $20 \%$ homogenate was centrifuged for $10 \mathrm{~min}$, at $600 \times g$ and $4^{\circ} \mathrm{C}$. To get rid of small molecules, PD-10 Sephadex columns (G-25M) were loaded with supernatant fluids and washed with buffer. Extracts were immediately used in the assays or stored at $-80^{\circ} \mathrm{C}$.

\subsection{Inhibitors}

The AK inhibitor NSC 113939 was a gift of the National Cancer Institute (Bethesda, MD, USA). 5-Iodotubercidin (4-amino-5-iodo-7-( $\beta$-D-ribofuranosyl)pyrrolo [2,3-d]pyrimidine), another AK inhibitor, was obtained from Research Biochemicals (Natick, MA, USA). The ADA inhibitor pentostatin ( 2 '-deoxycoformycin, i.e., R-3(2-deoxy- $\beta$-D-erythro-pentofuranosyl)-3,6,7,8-tetrahydro[4, 5-d][1,3]diazapin-8-ol) was from Parke-Davis (Detroit, MI, USA). EHNA, an alternative ADA inhibitor, was a gift from Wellcome Research Laboratories (Beckenham, Kent, UK). AOPCP, a potent membrane 5'-NT inhibitor, was bought from Sigma (St. Louis, MO, USA).

\subsection{Determination of enzyme kinetics}

Assays were carried out at $30^{\circ} \mathrm{C}$. The half-saturation constant $\left(K_{\mathrm{m}}\right)$ and the maximal activity $\left(V_{\max }\right)$ were determined, using Lineweaver-Burk linearization of the Michaelis-Menten equation [12]. One unit is $1 \mu \mathrm{mol}$ substrate converted in one min or $1 \mu \mathrm{mol}$ product formed in one min at $30^{\circ} \mathrm{C}$. Values are presented as the mean \pm S.E.

The activity of $\mathrm{AK}$ was measured with the radiometric method described by De Jong et al. [13]. There was no difference in results obtained with fresh and frozen (for $\leq 2$ days) supernatant fluids. The incubation mixture contained $40 \mathrm{mM}$ potassium phosphate $(\mathrm{pH} 7.0), 1.0 \mathrm{mM}$ GTP-lithium salt, $1.0 \mathrm{mM} \mathrm{MgCl}$, bovine serum albumin $0.05 \mathrm{mg} / \mathrm{ml}$, and [U- ${ }^{14} \mathrm{C}$ ]adenosine $(0.2-10 \mu \mathrm{M})$. After $10 \mathrm{~min}$ incubations were stopped by distribution of aliquots from the reaction mixture on squares of DEAE-cellulose (Whatman DE81) to bind the reaction product, $\left[{ }^{14}-\mathrm{C}\right] \mathrm{AMP}$. The squares were washed with $1 \mathrm{mM}$ ammonium formate, water and ethanol.

ADA activity was determined spectrophotometrically (Hitachi U-2000 double-beam) at $265 \mathrm{~nm}$ according to Coddington [14]. During $5 \mathrm{~min}$ incubations the conversion of adenosine to inosine was measured in $50 \mathrm{mM}$ potassium phosphate buffer ( $\mathrm{pH}$ 7.4) with substrate concentrations between 2 and $100 \mu \mathrm{M}$.

The NP activity was analyzed spectrophotometrically (Hitachi U-2000 double-beam) at $293 \mathrm{~nm}$ during $5 \mathrm{~min}$ based on the method of Coddington [15] with modifications. Present were $0.1 \mathrm{M}$ Tris ( $\mathrm{pH}$ 7.4), xanthine oxidase $0.1 \mathrm{U} / \mathrm{ml}$, and either various concentrations of $\mathrm{KH}_{2} \mathrm{PO}_{4}$ (0.1-50 mM) with $0.3 \mathrm{mM}$ inosine, or various concentrations of inosine $(0.02-1.0 \mathrm{mM})$ with $0.1 \mathrm{M} \mathrm{K}^{+}$-phosphate buffer ( $\mathrm{pH} 7.4$ ).

The incubation mixture for the HGPRT determination contained $0.4 \mathrm{mM}$ hypoxanthine, $0.5 \mathrm{M}$ Tris $/ 0.05 \mathrm{M}$ $\mathrm{MgCl}_{2}$ (pH7.4), $8 \mathrm{mM}$ PRPP and $10 \%$ Triton X-100 in the ratio $10: 10: 10: 1$. The reaction was started by adding 10 $\mu \mathrm{l}$ supernatant fluid to $50 \mu \mathrm{l}$ incubation mixture. After $120 \mathrm{~min}$ at $30^{\circ} \mathrm{C}$ the reaction was stopped with $\mathrm{HClO}_{4}(0.4$ $M$ final concentration). Samples were kept on ice for 10 
min and centrifuged for $4 \mathrm{~min}, 15000 \times g$ at $4^{\circ} \mathrm{C} . \mathrm{K}_{2} \mathrm{HPO}_{4}$ was added to $50 \mu \mathrm{l}$ supernatant fluid in a final concentration of $0.14 \mathrm{M}$. The samples were analyzed on HPLC as described previously [16].

For AMP-D determination Moss' method [17] modified by Meghji et al. [5] was used. The reaction mixture contained $20 \mathrm{mM}$ sodium dimethylglutarate $(\mathrm{pH} 7.0), 1$ mM EDTA, $0.1 \mathrm{mM}$ dithiothreitol, $0.15 \mathrm{M} \mathrm{KCl}, 1 \mu \mathrm{M}$ EHNA, $1 \mathrm{mM} \mathrm{ATP}$, and AMP in the range $0.5-15 \mathrm{mM}$. The reaction was stopped with $50 \% \mathrm{HClO}_{4}$ after $20 \mathrm{~min}$. After centrifugation for $5 \mathrm{~min}$ at $4^{\circ} \mathrm{C}, 15000 \times g$, supernatant fluids were taken and neutralized with $1.2 \mathrm{M}$ $\mathrm{K}_{2} \mathrm{CO}_{3} / 30 \mathrm{mM}$ EDTA. After centrifugation the supernatant fluid was taken to estimate ammonia spectrophotometrically at $625 \mathrm{~nm}$ according to Chaney and Marbach [18].

$5^{\prime}$-NT was determined at $37^{\circ} \mathrm{C}$ as described by Skladanowski et al. [19]. The assay is based on the method of Newby [20] with some modifications for 5'-nucleotidases of different specificity [21]. For both assays the conditions adopted secured lack of cross reactivity of the two forms. Briefly, the final concentrations in the incubation mixture for the AMP-specific form of $5^{\prime}$-NT were: $100 \mathrm{mM}$ TES (or Hepes) $/ \mathrm{NaOH}, \mathrm{pH} 7.0,10 \mathrm{mM} \mathrm{MgCl}{ }_{2}$, $30 \mathrm{mM} \mathrm{NaCl}, 1 \mathrm{mM}$ ADP and AMP between $0.5-20 \mathrm{mM}$. To prevent conversion of adenosine to AMP and/or inosine, $2 \mu \mathrm{M}$ 5-iodotubercidin and $10 \mu \mathrm{M}$ EHNA were included. The reaction was stopped with $50 \mu \mathrm{l} 1.3 \mathrm{M}$ $\mathrm{HClO}_{4}$ after 1.5 to $3 \mathrm{~min}$. Samples were kept on ice for 30 min, deproteinized, centrifuged and analyzed with HPLC [22]. The incubation conditions for the IMP-specific form of $5^{\prime}$-NT were: $100 \mathrm{mM}$ imidazole $/ \mathrm{HCl}, \mathrm{pH} 6.5,50 \mathrm{mM}$ $\mathrm{MgCl}_{2}, 500 \mathrm{mM} \mathrm{NaCl}, 2.5 \mathrm{mM}$ IMP and $2.5 \mathrm{mM}$ ATP. The time course was linear for both assays. We recalculated the results from the earlier study [19] for $30^{\circ} \mathrm{C}$, using factors of 0.75 for human and 0.71 for rat AMP- and IMP-preferred $5^{\prime}$-NT, which we determined experimentally.

\section{Results and discussion}

\subsection{Adenosine kinase}

Use of the AK inhibitors NSC $113939(50 \mu \mathrm{M})$ and 5-iodotubercidin ( $5 \mu \mathrm{M})$, proved that our AK measurements were specific; they inhibited the reaction almost completely ( $94 \%$ and $96 \%$, respectively). Inclusion of the ADA inhibitor pentostatin $(1 \mu \mathrm{M})$ in the reaction mixture did not change the $V_{\text {max }}$, which shows that ADA did not interfere with the assay. Addition of AOPCP $(50 \mu \mathrm{M})$, a potent membrane $5^{\prime}$-NT inhibitor [23], had no influence on the AK activity. We avoided thus possible product conversion by ecto- $5^{\prime}-\mathrm{NT}$ in the assay. The $V_{\max }$ of $\mathrm{AK}$ in human myocardial homogenates was the same as in rat heart (Table 1). In both species, the $K_{\mathrm{m}}$-values were in the low micromolar range (Table 1). The observed species-differences are in line with those suggested earlier [25].

\subsection{Adenosine deaminase}

The inhibitor pentostatin $(3 \mu \mathrm{M})$ completely abolished ADA activity, showing that other reactions did not interfere with our assay. In human heart the $V_{\max }$ was about $30 \%$ of that in rat heart (Table 1); however, the $K_{\mathrm{m}}$-values were almost identical (Table 1). Our results on ADA activity in human and rat heart agree with those published by Meghji et al. [5], although they made only one-point estimations. The kinetic data on rat heart are in line with Arch and Newsholme [26].

Table 1

Maximal activity $\left(V_{\max }\right)$ and half-saturation constants $\left(K_{\mathrm{m}}\right)$ of the adenylate-metabolizing enzymes (E) in rat and human hearts

\begin{tabular}{|c|c|c|c|c|c|}
\hline \multirow[t]{2}{*}{ Enzyme } & \multirow[t]{2}{*}{ Substrate } & \multicolumn{2}{|c|}{$V_{\max }(\mathrm{mU} / \mathrm{g}$ wet weight $)$} & \multicolumn{2}{|l|}{$K_{\mathrm{m}}(\mu \mathrm{M})$} \\
\hline & & Rat & Human & Rat & Human \\
\hline$\overline{\mathrm{AK}}$ & adenosine & $38.9 \pm 3.2(3)$ & $37.7 \pm 0.8(9)$ & $2.30 \pm 0.20(3)$ & $2.06 \pm 0.13(9)$ \\
\hline $\mathrm{ADA}$ & adenosine & $715 \pm 36(3)$ & $212 \pm 17(11)$ & $21.0 \pm 0.5(3)$ & $20.3 \pm 3.5(11)$ \\
\hline \multirow[t]{2}{*}{ NP } & inosine & $738 \pm 52(3)$ & $245 \pm 25(8)$ & $60.7 \pm 8.6(3)$ & $62.1 \pm 4.8(8)$ \\
\hline & $P_{i}$ & $441 \pm 26(6)$ & $134 \pm 12(5)$ & $1540 \pm 100(6)$ & $2070 \pm 570(5)$ \\
\hline \multirow[t]{2}{*}{ XOD } & xanthine & $38.6 \pm 1.8(5)^{a}$ & $<1$ & $4.5 \pm 0.4(5)^{a}$ & n.d. \\
\hline & hypoxanthine & $38.1 \pm 4.3(5)$ & $<1$ & $3.0 \pm 0.3(5)^{a}$ & n.d. \\
\hline HGPRT & hypoxanthine & $299 \pm 44(5)$ & $36.0 \pm 2.6(5)$ & N.D. & N.D. \\
\hline AMP-D & AMP & $1837 \pm 152(3)$ & $976 \pm 20(5)$ & $1120 \pm 130(3)$ & $2780 \pm 180(5)$ \\
\hline \multirow[t]{2}{*}{$5^{\prime}-\mathrm{NT}$} & AMP & $362 \pm 17(3)$ & $128 \pm 37(6)$ & $1220 \pm 70(3)$ & $5320 \pm 570(6)$ \\
\hline & IMP & $533 \pm 11(5)$ & $35 \pm 9(6)$ & $20 \pm 30(5)$ & $510 \pm 70(6)$ \\
\hline
\end{tabular}

Enzyme assays were done on myocardial supernatant fluids. The activity of the catabolizing enzymes proved to be in human heart $12-50 \%$ of that in rat heart; the activity of adenosine kinase was the same in both species. In human heart the $K_{\mathrm{m}}$-values were in the same order of magnitude as in rat heart, although they were at least twice higher for mononucleotide-catabolizing enzymes. Mean \pm S.E. with number of experiments in parentheses. For abbreviations, see legend to Fig. 1. n.d., not detectable. N.D., not determined.

a Data from [24]. 


\subsection{Nucleoside phosphorylase}

In human myocardial tissue, the $V_{\max }$ of NP with inosine or $\mathrm{KH}_{2} \mathrm{PO}_{4}$ as variable substrate was about $30 \%$ of that in rat (Table 1). The $V_{\max }$ estimated with varying inosine concentrations was about twice higher than with $\mathrm{KH}_{2} \mathrm{PO}_{4}$ as variable substrate. This could be attributed to inhibition by the Tris-buffer used when phosphate was varied. The $K_{\mathrm{m}}$, however, was similar in both species (Table 1). We are unaware of kinetic data on human NP activity except for a qualitative estimation of activity in human and rat heart [27].

\subsection{Xanthine oxidoreductase}

Earlier our group could not detect XOD activity in human-heart homogenate. We found a very low activity in perfused diseased human hearts [28], agreeing with the results of others [see, e.g., [29,30]]. In rat heart we determined activity [31] and kinetic data for XOD with hypoxanthine and xanthine as substrate [24]. For both substrates the $V_{\max }$-values were the same; the $K_{\mathrm{m}}$-values were in the lower micromolar range (Table 1).

\subsection{Hypoxanthine guanine phosphoribosyltransferase}

In human heart the $V_{\max }$ of HGPRT with hypoxanthine as substrate was only $12 \%$ of the value for rat heart. Purine degradation, but also purine salvage to IMP via HGPRT, appears slow in human heart compared with rat heart.

\subsection{AMP deaminase}

Side reactions only interfered in rat heart at substrate concentrations higher than $15 \mathrm{mM}$ by an artifactual sharp increase of ammonia production. The dependence of ammonia production on AMP concentration was biphasic in rat- but not in human-heart homogenate. HPLC analysis of the postreactional mixtures revealed that the accelerated ammonia production at $\geq 15 \mathrm{mM}$ AMP correlated with formation of adenosine and inosine. Then the EHNA concentration $(1 \mu \mathrm{M})$ seemed too low to inhibit ADA completely. At low concentrations of AMP, the production of adenosine, if detectable, was not accompanied by increased inosine, showing effective inhibition of ADA. We decided to estimate activity values at substrate concentrations $\leq 10 \mathrm{mM}$. Then we observed a $V_{\max }$ for rat heart AMP-D twice higher than for human heart, where the delayed increase of ammonia did not take place (Table 1). The $K_{\mathrm{m}}$-values for AMP-D were similar in human and rat heart, i.e., in the lower millimolar range (Table 1). We found lower activities of AMP-D in both species than Meghji et al. [5]. This is presumably due to their overestimation caused by EHNA's incomplete inhibition of ADA at $25 \mathrm{mM}$ AMP. The presence of $1 \mathrm{mM}$ ATP in the AMP-D assay ensured that the sigmoidal curve turned into a hyperbolic one. Our findings partly confirm other literature data on rat $[32,33]$ and human heart [34].

\subsection{5'-Nucleotidase}

In human heart the $V_{\max }$ of AMP- and IMP-preferred 5 -NT was $25-30 \%$ of that in rat heart (Table 1). The $K_{\mathrm{m}}$-values for both substrates were 2-4 times higher in human heart (Table 1), suggesting a lower affinity of 5 -NT for AMP and IMP in man. Our results in rat heart were comparable with those from Truong et al. [35]. We found a 13-fold lower initial concentration of inosine accumulated in freshly prepared human-heart supernatant fluids compared to rat-heart ones. Concentrations were $8.6 \pm 1.2 \mu \mathrm{M}(n=7)$ and $116 \pm 3 \mu \mathrm{M}(n=7)$, respectively. Additive effects of lower AMP dephosphorylation by $5^{\prime}$-NT and adenosine deamination by ADA in the human heart caused this difference with rat heart.

\subsection{Physiological implications}

One has to be cautious in the interpretation of the $V_{\max }$ of a particular reaction. We realize that we calculated kinetic values on enzymes present in cytosol, not on purified proteins. On the other hand, we avoided the instability problems sometimes seen with purified enzymes. In human myocardium the maximum velocities of the enzymes catabolizing adenylate to hypoxanthine (AMP-D, AMP- and IMP-specific 5'-NT, ADA and NP) were in a highly regular order $25-50 \%$ of those in rat heart. The $V_{\max }$ of the anabolic enzyme AK was the same in both species, whereas the maximal HGPRT activity for human heart was only $12 \%$ of that observed for rat. We found the $K_{\mathrm{m}}$-values of AK, ADA and NP to be either the same or in the same order of magnitude for both species. Thus we expect that the affinity of these enzymes to their substrates is similar. The $K_{\mathrm{m}}$-values of AMP-D and $5^{\prime}$-NT (AMP/IMP) were higher in human than in rat heart, suggesting a lower affinity of these two enzymes in human heart. Slower purine breakdown but not purine salvage via AK possibly protects the human heart at an earlier stage through purine accumulation instead of rapid breakdown to urate. Maintenance of the cardiac nucleotide pool may play a more important role in man than in rat.

A possible difference in tissue adenosine levels between human and rat heart may be assessed by relating the flux rate determined from AMP to adenosine with the rate of adenosine degradation to inosine. From the data (Table 1) it appears that the lower $V_{\max }$-value for $5^{\prime}$-nucleotidase in human heart is compensated by slower adenosine catabolism.

Borst et al. [36] determined kinetic values for SAH hydrolase in patients with hypertrophic obstructive cardiomyopathy. Its activity is very low compared to the other enzyme activities involved in purine metabolism in human heart. We reported earlier that SAH hydrolase activity does 
not contribute significantly to adenosine during ischemia, but could play a role during normoxia [37].

Our results give the maximal velocity obtainable and affinity toward substrates for the enzymes investigated. Free cytosolic AMP-concentrations in cardiomyocytes are probably in the submicromolar range even under ischemic conditions [38]. This is far below the $K_{\mathrm{m}}$ of $5^{\prime}-\mathrm{NT}$ and AMP-D. We suggest that the rise in AMP-concentration due to hypoxia will give a large response in adenosine formation, reinforced by allosteric activation of $5^{\prime}-\mathrm{NT}$. The next step is the rapid conversion to inosine by ADA (see Table 1).

The breakdown of inosine to hypoxanthine by NP depends on the concentration of phosphate. Its physiological concentration in rat heart exceeds the $K_{\mathrm{m}}$ (phosphate) for NP by a factor of 1.5 [39]. When the free phosphate concentration rises (about three times) due to ischemia, the activity of NP might increase, approaching the $V_{\max }$-value. Thus, the intracellular phosphate concentration is possibly rate-limiting for adenosine degradation to hypoxanthine. We confirmed this in our AMP-specific 5'-NT assay: the amount of inosine present in the supernatant fluid - stoichiometric with phosphate liberated from AMP - was converted to hypoxanthine by NP both in rat and human heart. Hypoxanthine salvage to IMP by HGPRT in human heart is possible but slow.

\subsection{Cardiac IMP production}

In skeletal muscle and liver, IMP produces inosine. There is consensus that in ischemic heart muscle like in brain, AMP degradation via adenosine is preferred. Olsson and Pearson suggested that the IMP pathway is dominant in cells generating ATP predominantly through anaerobic glycolysis; the adenosine pathway seems prominent in organs relying on oxidative phosphorylation [40]. Our in vitro data would show that the capacity of the IMP pathway exceeds the adenosine pathway in both species (see Table 1).

Association with membrane phospholipids activates AMP-D [41]. Recently, Tanfani et al. suggested that synchronized AMP-D inhibition by ATP decrease and this association loss in ischemic heart shifts adenylate to adenosine production by $5^{\prime}$-NT [41]. The cardioplegia-arrested human heart produces considerable amounts of adenosine besides inosine $[42,43]$. However, IMP accumulates in human heart as well [43].

\subsection{Limitations of the study}

We measured the kinetics of the enzymes in homogenates, which consist of endothelial cells (ca. 4\%) and cardiomyocytes. The localization of the enzymes in myocytes and/or endothelial cells differs in species. For example, nucleoside phosphorylase in guinea-pig heart is completely localized in the endothelial cells [44]; in rat heart we found this enzyme to be also present in the myocytes [11]. It is not known if the distribution of the enzymes discussed in this paper is the same in rat and human heart. We also did not deal with kinetics of nucleoside transport in cardiomyocytes and endothelial cells in this study. We only measured the kinetics of the enzymes involved in purine metabolism under optimal conditions in human and rat heart.

\subsection{Conclusion}

Human heart with its slower rate of adenosine formation from AMP, its lower activity of purine-catabolizing enzymes and its virtual absence of XOD, is less geared to adenosine production and subsequent degradation than rat heart.

\section{Acknowledgements}

We are grateful to Ms. E. Keijzer for excellent technical assistance and to Dr. R.T. Smoleński for solving logistic problems. The Netherlands Heart Foundation (grant 90.272), the Polish Committee for Scientific Research (grant 440349102 ) and the European Community (COST grant 6885) financially supported this study.

\section{References}

[1] Belardinelli, L. and West, G.A. (1988) in Myocardial Energy Metabolism (De Jong, J.W., ed.), pp. 93-104, Nijhoff Publ., Dordrecht.

[2] Lin, J.-L., Wilber, D.J., Du, D., Pearlman, J., Ruskin, J.N. and Garan, H. (1991) Circulation 84, 1319-1332.

[3] Zimmermann, H. (1992) Biochem. J. 285, 345-365.

[4] Meghji, P., Middleton, K.M., Hassall, C.J.S., Phillips, M.I. and Newby, A.C. (1988) Int. J. Biochem. 20, 1335-1341.

[5] Meghji, P., Middleton, K.M. and Newby, A.C. (1988) Biochem. J. 249, 695-703.

[6] Emerit, I., Fabiani, J.N., Ponzio, O., Murday, A., Lunel, F. and Carpentier, A. (1988) Ann. Thorac. Surg. 46, 619-624.

[7] Di Lello, F., Flemma, R.J., Anderson, A.J., Mullen, D.C., Kleinman, L.H. and Werner, P.H. (1989) Ann. Thorac. Surg. 47, 51-61.

[8] Swanson, D.K., Pasaoglu, I., Berkoff, H.A., Southard, J.A. and Hegge, J.O. (1988) J. Heart Transplant. 7, 456-467.

[9] Czarnecki, W. and Czarnecki, A. (1989) Pharmacol. Res. 21, 587594.

[10] De Jong, J.W., Czarnecki, W., Ruzyllo, W., Huizer, T. and Herbaczyńska-Cedro, K. (1989) Cardiovasc. Res. 23, 484-488.

[11] De Jong, J.W., Keijzer, E., Huizer, T, and Schoutsen, B. (1990) J. Mol. Cell. Cardiol. 22, 1065-1070.

[12] Dixon, M. and Webb, E.C. (1979) Enzymes. pp. 55-62, Longman, London.

[13] De Jong, J.W., Keijzer, E., Uitendaal, M.P. and Harmsen, E. (1980) Anal. Biochem. 101, 407-412.

[14] Coddington, A. (1965) Biochim. Biophys. Acta 99, 442-451.

[15] Coddington, A. (1974) in Methods of Enzymatic Analysis (Bergmeyer, H.U., ed.) pp. 1932-1934, Verlag Chemie, Weinheim and Academic Press, New York. 
[16] Stolk, J.N., De Abreu, R.A., Boerbooms, A.M.Th., De Koning, D.G.M., De Graaf, R., Kerstens, P.J.S.M. and Van De Putte, L.B.A. (1995) J. Chromatogr. B: Biomed. Appl., in press.

[17] Moss, K.M. (1977) FEBS Lett. 75, 141-144.

[18] Chaney, A.L. and Marbach, E.P. (1962) Clin. Chem. 8, 130-132.

[19] Skladanowski, A.C., Makarewicz, W., Tavenier, M., De Jong, J.W. and Zydowo, M.M. (1994) Drug Dev. Res. 31, 322 (Abstr.).

[20] Newby, A.C. (1988) Biochem. J. 253, 123-130

[21] Skladanowski, A.C. and Newby, A.C. (1990) Biochem. J. 268, $117-122$.

[22] Smoleński, R.T., Lachno, D.R., Ledingham, S.J.M. and Yacoub, M.H. (1990) J. Chromatogr. 527, 414-420.

[23] Schütz, W., Schrader, J. and Gerlach, E. (1981) Am. J. Physiol. 240, H963-H970.

[24] Janssen, M., Tavenier, M., Koster, J.F. and De Jong, J.W. (1993) Biochim. Biophys. Acta 1156, 307-312.

[25] De Jong, J.W. (1977) Arch. Int. Physiol. Biochim. 85, 557-569.

[26] Arch, J.R.S. and Newsholme, E.A. (1978) Biochem. J. 174, 965-977.

[27] Smoleński, R.T., De Jong, J.W., Janssen, M., Lachno, D.R., Żydowo, M.M., Tavenier, M., Huizer, T. and Yacoub, M.H. (1993) J. Mol. Cell Cardiol. 25, 67-74.

[28] De Jong, J.W., Van der Meer, P., Nieukoop, A.S., Huizer, T., Stroeve, R.J. and Bos, E. (1990) Circ. Res. 67, 770-773.

[29] Podzuweit, T., Beck, H., Müller, A., Bader, R., Görlach, G. and Scheld, H.H. (1991) Cardiovasc. Res. 25, 820-830.

[30] Wright, R.M., Vaitaitis, G.M., Wilson, C.M., Repine, T.B., Terada, L.S. and Repine, J.E. (1993) Proc. Natl. Acad. Sci. USA 90, 10690-10694.

[31] Schoutsen, B., De Jong, J.W., Harmsen, E., De Tombe, P.P. and Achterberg, P.W. (1983) Biochim. Biophys. Acta 762, 519-524.
[32] Kaletha, K. and Skladanowski, A.C. (1979) Biochim. Biophys. Acta $568,80-90$

[33] Spychala, J. and Marszalek, J. (1991) Int. J. Biochem. 23, 1155 1159.

[34] Kaletha, K., Skladanowski, A.C., Bogdanowicz, S. and Żydowo M. (1979) Int. J. Biochem. 10, 925-929.

[35] Truong, V.L., Collinson, A.R. and Lowenstein, J.M. (1988) Biochem. J. $253,117-121$.

[36] Borst, M.M., Deussen, A. and Schrader, J. (1992) Cardiovasc. Res. 26, 143-147.

[37] Achterberg, P.W., De Tombe, P.P., Harmsen, E. and De Jong, J.W. (1985) Biochim. Biophys. Acta 840, 393-400.

[38] Bünger, R. (1987) in Topics and Perspectives in Adenosine Research (Gerlach, E. and Becker, B.F., eds.) pp. 223-234, SpringerVerlag, Berlin.

[39] Bradamante, S., De Jong, J.W. and Piccinini, F. (1993) Biochem. Biophys. Res. Commun. 196, 872-878.

[40] Olsson, R.A. and Pearson, J.D. (1990) Physiol. Rev. 70, 761-845.

[41] Tanfani, F., Kossowska, E., Purzycka-Preis, J., Żydowo, M.M., Wozniak, M., Tartaglini, E. and Bertoli, E. (1993) Biochem. J. 291, 921-926.

[42] Smoleński, R.T., Skladanowski, A.C., Perko, M. and Żydowo, M.M. (1989) Clin. Chim. Acta 182, 63-74.

[43] Smoleński, R.T., Skladanowski, A.C., Swierczyński, J., Perko, M., Narkiewicz, M. and Zydowo, M.M. (1993) Acta Biochim. Polon. $40,531-538$

[44] Rubio, R. and Berne, R.M. (1980) Am. J. Physiol. 239, H721-H730. 